\title{
Traumatic cyclodialysis
}

\section{A case report}

\author{
E. AVIEL, AND R. AVISAR \\ From the Barzilai Medical Centre, Ashkelon, Israel
}

Traumatic cyclodialysis has been reported by several authors during the last decade (Sedan, 1966; Turut, Constantinides, and Asseman, I97I). Romem and Singer (1973) described a case of traumatic aniridia without prolapse of iris through an external wound. Trobe and Keeney (1974) reported three cases of traumatic aniridia all of which were accompanied by perforating wounds involving the cornea.

This is a report of a case of traumatic cyclodialysis with extrusion of most of the iris through a scleral perforation.

\section{Case report}

A 25-year-old White female agricultural worker was admitted to the ophthalmic department of the Barzilai Medical Centre, Ashkelon, after an injury to her left eye caused by a screwdriver (Figure). The injury had been accidentally self-inflicted two hours earlier as she had been trying to repair a tubing of metal in the cow-shed.

The visual acuity in the right eye was $6 / 6$, and examination of that eye including the fundus revealed nothing abnormal. The visual acuity in the left eye was hand movements with good perception of light. The upper lid was swollen with ecchymoses and abrasions of the skin. There was conjunctival injection. On the medial side about $4 \mathrm{~mm}$ from the limbus, a brown oval mass could be seen under the abraded conjunctiva. The cornea was clear and did not show any signs of perforation. The anterior chamber was filled with blood and it was impossible to see any further details. The eye was hypotonic, tension by Schiötz tonometry was $5 \cdot 5 / 16$.

It was decided to proceed with exploration of the ocular injury under general anaesthesia. An operation was performed on the day of admission. On exposure of the sclera medially, a mass of soft brown tissue was seen within the scleral wound which extended along a course roughly parallel to the limbus from 7.0 o'clock $3 \mathrm{~mm}$ from the limbus to 10.0 o'clock $9 \mathrm{~mm}$ from the limbus. It was necessary to separate the medial rectus from its insertion to obtain adequate exposure of the scleral wound. The brown mass was identified as prolapsed iris and it was excised level with the sclera. After the excision the intact ciliary body was seen in the

Address for reprints: Dr E. Aviel, Barzilai Medical Centre, Ashkelon, Israel scleral wound. There was no bleeding from the ciliary body and no vitreous could be seen throughout the whole procedure. The scleral wound was sutured with interrupted $7-0$ silk sutures. As the edges of the scleral wound were brought in apposition the presenting ciliary body was reposited with a thin iris spatula. The edges of the upper end of the scleral wound $9 \mathrm{~mm}$ from the limbus were treated with superficial diathermy. The medial rectus was re-attached to its insertion. The hyphaema was washed out through a keratome incision in the temporal corneal periphery. Evacuation of the hyphaema allowed visualization of a clear intact lens; in the postoperative period hyphaema filled one-third

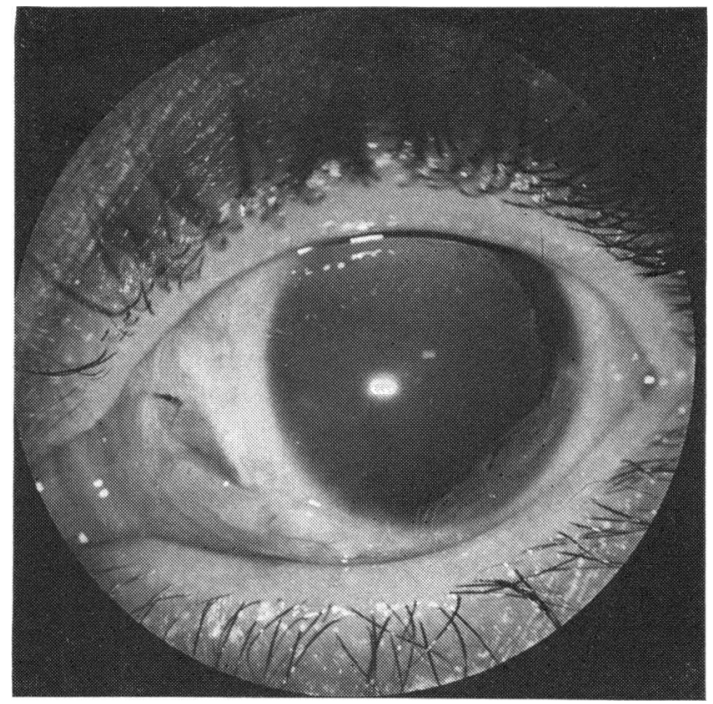

of the anterior chamber one week after the operation. The cornea remained clear throughout. The anterior chamber appeared to be of average depth. From 4.0 to 5.0 o'clock, remnants of iris could be seen. The lens was mostly clear with a layer of blood clot adherent to its posterior aspect in the lower nasal quadrant. Fundus details could not be clearly seen. Intraocular pressure was $8 \mathrm{mmHg}$ by applanation tonometry. The eye was dressed daily with atropine drops and an antibiotic ointment; systemic corticosteroid treatment was started on the tenth postoperative day.

One month after the injury the visual acuity with pinhole correction was $6 / 18$. The eye was quiet and the 
cornea clear. There was no aqueous flare in the anterior chamber. The lens could now be seen to be subluxated medially. The taut zonules could be seen at the equator of the lens from I.0 to 4.0 o'clock. Fundus details could now be visualized and there were no pathological findings, but the lower nasal quadrant could still not be seen as the blood remnants obscured the posterior aspect of the lens in this area.

On gonioscopy, in most of the nasal half, the angle structures were hidden by the equator of the subluxated lens. From II.0 to 3.0 o'clock, ciliary processes stretched by the taut zonules could be seen. From 3.0 to 6.0 o'clock there was traumatic recession of the angle of the anterior chamber.

One year after the injury the visual acuity in the left eye is $6 / 6$ with pinhole correction. The intraocular pressure is $15 \mathrm{mmHg}$ by applanation tonometry. There is no change in the slit-lamp and fundoscopic findings.

\section{Discussion}

Sedan (1966) and Turut and others (197I) reported cases of traumatic cyclodialysis without corneoscleral wound. These cases could be described as traumatic recess of the angle of the anterior cham- ber. In Turut's two cases the hypotonia that appeared supports the view that there was a cyclodialysis cleft as a result of the injury. Duke-Elder (1972) described a case in which the ciliary body was completely torn from its anterior scleral attachment with backward displacement of the iris; there was a continuity between the anterior chamber and the suprachoroidal space. Such an injury may give the appearance of aniridia.

The case reported here differs in that the iris extruded from the scleral wound. There was no vitreous presentation and no haemorrhage from the wound. It is therefore assumed that the ciliary body remained intact in spite of the severe trauma. The sharp edge of the instrument produced the pathway for the iris prolapse after tearing most of it out from its root.

The final visual acuity of $6 / 6$ is in keeping with the results of Trobe and Keeney (1974) who reported a final visual acuity of $20 / 25$ in three cases of traumatic aniridia. In our case the intraocular pressure is still normal one year after the injury.

\section{References}

DUKE-ELDER, s. (1972) 'System of Ophthalmology', vol. XIV, p. I 10. Kimpton, London ROMEM, M., and SINGER, L. (1973) Brit. F. Ophthal., 57, 61 3

SEDAN, J. (1966) Bull. Soc. Ophtal. Fr., 66, 954

TROBE, J. D., and KEENEY, H. A. (1974) Amer. F. Ophthal., 78, 1006

TURUt, P., CONSTANTINIDES, G., and ASSEMAN, R. (1971) Bull. Soc. Ophtal. Fr., 71, 760 